\title{
Mapping fracture flow paths with a nanoscale zero-valent iron tracer test and a flowmeter test
}

\author{
Po-Yu Chuang ${ }^{1} \cdot$ Yeeping Chia ${ }^{1} \cdot$ Yung-Chia Chiu $^{2} \cdot$ Mao-Hua Teng ${ }^{1}$. \\ Sofia Ya Hsuan Liou ${ }^{1}$
}

Received: 7 February 2017 / Accepted: 17 July 2017 / Published online: 14 August 2017

(C) The Author(s) 2017. This article is an open access publication

\begin{abstract}
The detection of preferential flow paths and the characterization of their hydraulic properties are important for the development of hydrogeological conceptual models in fractured-rock aquifers. In this study, nanoscale zerovalent iron (nZVI) particles were used as tracers to characterize fracture connectivity between two boreholes in fractured rock. A magnet array was installed vertically in the observation well to attract arriving nZVI particles and identify the location of the incoming tracer. Heat-pulse flowmeter tests were conducted to delineate the permeable fractures in the two wells for the design of the tracer test. The nZVI slurry was released in the screened injection well. The arrival of the slurry in the observation well was detected by an increase in electrical conductivity, while the depth of the connected fracture was identified by the distribution of nZVI particles attracted to the magnet array. The position where the maximum weight of attracted nZVI particles was observed coincides with the depth of a permeable fracture zone delineated by the heat-pulse flowmeter. In addition, a saline tracer test produced comparable results with the nZVI tracer test. Numerical simulation was performed using MODFLOW with MT3DMS to estimate the hydraulic
\end{abstract}

Electronic supplementary material The online version of this article (doi:10.1007/s10040-017-1651-8) contains supplementary material, which is available to authorized users.

Yeeping Chia

ypc@ntu.edu.tw

1 Department of Geosciences, National Taiwan University, No. 1, Sec. 4, Roosevelt Rd, Taipei 106, Taiwan

2 Institute of Applied Geosciences, National Taiwan Ocean University, No. 2, Beining Rd, Keelung 202, Taiwan properties of the connected fracture zones between the two wells. The study results indicate that the nZVI particle could be a promising tracer for the characterization of flow paths in fractured rock.

Keywords Fractured rocks $\cdot$ Flowmeter $\cdot$ Nanoscale zero-valent iron $\cdot$ Tracer tests $\cdot$ Flow paths

\section{Introduction}

The detailed characterization of preferential flow in fractured bedrock aquifers is important for the water resource management as well as the investigation of contaminant pathways (Neuman 2005). Because a fractured rock aquifer is heterogeneous and anisotropic, the delineation of flow paths is much more difficult than in an unconsolidated aquifer, resulting in a relatively poor understanding of how groundwater flow occurs in the fractured rock aquifer. Borehole geophysical techniques usually investigate permeable zones based on the distribution of fractures (Barton et al. 1995; Williams and Johnson 2000). However, groundwater is often found to flow through only a few permeable fractures (Berkowitz 2002). The distribution of hydraulic conductivity in an open hole can be estimated from a packer test (Braester and Thunvik 1984; Zhao 1998), but its operation is time-consuming and its resolution is restricted to the test interval. Electrical conductivity logging can be used to detect the permeable zones in a borehole (Tsang et al. 1990). Recent development of the distributed temperature sensing technology can be used to characterize the permeable fractures and hydrogeological conditions in a single borehole (Banks et al. 2014; Read et al. 2014; Coleman et al. 2015; Bense et al. 2016; Sellwood et al. 2016), but the deployment of the downhole instrument may affect data acquisition (Bense 
et al. 2016; Sellwood et al. 2016). Heat-pulse flowmeter test can effectively investigate the vertical distribution of transmissive zones in the bedrock aquifer (Molz et al. 1994; Lee et al. 2012). The flowmeter test has also been used to indirectly infer the flow paths between boreholes (Williams and Paillet 2002).

The solute tracer test was performed to delineate a single fracture in field experiments with comprehensive welllogging data (Novakowski and Lapcevic 1994; Lapcevic et al. 1999), but frequent sampling and analysis is expensive and time consuming. The hydraulic tomography approach can be used to indirectly infer the fracture connectivity (Hao et al. 2008; Sharmeen et al. 2012; Zha et al. 2014, 2015, 2016); however, spatial resolution of the inferred tomograms is controlled by the observation interval. Thermal tracer tests have been conducted to delineate fracture flow paths between boreholes (Ma et al. 2012; Read et al. 2013; Klepikova et al. 2014). The method can be used to detect the most transmissive fracture, but is not sensitive to identifying all flowing fractures in the borehole (Klepikova et al. 2014). Additional processes involved in heat transport and significant noises make it difficult to quantitatively interpret the temperature data from the thermal tracer experiment (Ma et al. 2012).

Nanoscale zero-valent iron (nZVI), an effective reducing reagent, has been used to remediate and remove various groundwater contaminants, such as chlorinated organic solvents, organochlorine pesticides, and PCBs (Wang and Zhang 1997; Varanasi et al. 2007). Chuang et al. (2016) developed an approach using nZVI particles as tracers to directly locate flow paths in fractured rock; however, most injected nZVI particles were found to aggregate and precipitate to the bottom of the injection well, resulting a low mass recovery rate of approximately $0.01 \%$. This would restrict the potential application of nZVI particles as tracers beyond the experimental range.

In this study, an improved nZVI tracer test was developed to characterize the flow paths in fractured rock. A laboratory flow system was established to examine the migration characteristics of nZVI slurry. Preliminary field tests at the study site were conducted for the design of the tracer tests. Two tracer tests were then conducted between a sealed injection well and an observation well with slotted casing, including a conventional saline tracer and a novel nZVI tracer, to compare test results. Lastly, a numerical model using MODFLOW with MT3DMS was developed to simulate the tracer transport through permeable fracture zones at the study site.

\section{Synthesis of nanoscale zero-valent iron}

nZVI particles were prepared by a chemical reduction method (Wang and Zhang 1997). Typically, nZVI can be synthesized by using sodium borohydride as the key reductant. The reaction was carried out by adding $0.5 \mathrm{~L}$ of $\mathrm{NaBH}_{4}(1.74 \mathrm{M})$ to $0.5 \mathrm{~L}$ of $\mathrm{FeCl}_{3} \cdot 6 \mathrm{H}_{2} \mathrm{O}(0.3 \mathrm{M})$ solution at a volume ratio of $1: 1$. Ferric iron is reduced by borohydride according to the following reaction:

$4 \mathrm{Fe}^{3+}+3 \mathrm{BH}_{4}^{-}+9 \mathrm{H}_{2} \mathrm{O} \rightarrow 4 \mathrm{Fe}^{0} \downarrow+3 \mathrm{H}_{2} \mathrm{BO}_{3}^{-}+12 \mathrm{H}^{+}+6 \mathrm{H}_{2}$

Due to magnetic attraction and van der Waals forces, nZVI particles can form aggregates and precipitate in a gelatinous state (Comba and Sethi 2009). Previous studies indicated that many surface-active agents can be used to make dispersible ink and toner (Williams et al. 2006; Phenrat et al. 2008). In this study, water-soluble polyethyleneimine (PEI) was used as a nanoparticle dispersant. PEI is a polymer that can provide the steric repulsive forces to form a colloidal suspension and reduce the aggregation of nZVI particles (Goon et al. 2009; Wang et al. 2009). Here, the PEI was mixed to a concentration of approximately $4 \times 10^{-4} \mathrm{M}$. Most of the nZVI particles produced in this study ranged from 50 to $100 \mathrm{~nm}$ in diameter. The solid content of the PEI-stabilized nZVI particles was about $8.6 \mathrm{~g} \mathrm{Fe} / \mathrm{L}$.

The laboratory synthesized nZVI slurry was composed of water, nZVI particles and water-soluble PEI. Previous studies (Phenrat et al. 2008; Tiraferri et al. 2008) indicated that nZVI particles were settled and fractionated by gravity in solution. Immediately after the synthesis of nZVI particles, they were observed to move downward. An interface between the supernatant and the subnatant was formed in $5 \mathrm{~min}$ and stabilized in less than $30 \mathrm{~min}$. The browncolored supernatant consisted of water, some PEI, a small amount of ferric oxide particles, and nZVI particles. The dark-colored subnatant consisted primarily of nZVI particles and PEI. nZVI particles settled to the bottom due to gravity effect, while PEI settled due to increased density from the aggregation of PEI molecules through short-range hydrogen bonds (Sidorov et al. 1999). Nearly all deposited nZVI particles were soaked in the PEI solution. Electrical conductivities of the PEI is approximately $2,100 \mu \mathrm{S} / \mathrm{cm}$. After the $\mathrm{ZVI}$ particles were added to the PEI, electrical conductivity of the well-mixed nZVI slurry increased to $3,120 \mu \mathrm{S} / \mathrm{cm}$. After the gravitational segregation, electrical conductivity of the supernatant reduced to $328 \mu \mathrm{S} / \mathrm{cm}$. Last, and most importantly, as nZVI particles are magnetic, they are attracted to magnets. This feature spurred the development of a magnet array for locating the position of incoming tracers. The magnet array assembly, which is used in both laboratory and field tests, consists of a $2-\mathrm{mm}$ steel cable, centralizers, and a number of neodymium magnets. There is an interval of $10 \mathrm{~cm}$ between the magnets and $1 \mathrm{~m}$ between the centralizers. The size of the magnet is $2.95 \times 1.25 \mathrm{~cm}$. 


\section{Laboratory test}

A laboratory test was contrived to simulate the migration processes of the nZVI slurry between two open holes connected by a single permeable fracture. Two $9.4-\mathrm{cm}$ diameter transparent acrylic vertical pipes were set up to simulate the injection and observation wells. A 40-cm-long horizontal transparent acrylic pipe was placed to connect the two vertical pipes at $24.8-28.9 \mathrm{~cm}$ above the bottom, as shown in Fig. 1. The horizontal pipe was filled with well-sorted fine sand to simulate a permeable conduit. An overflow condition resulted in a constant difference in hydraulic head of $20.4 \mathrm{~cm}$ between the two pipes, yielding an average hydraulic gradient of 0.51 . Two electrical conductivity sensors were placed respectively at the bottom of the injection pipe and $27.9 \mathrm{~cm}$ above the bottom, right adjacent to the permeable conduit, in the observation pipe. In addition, a $40-\mathrm{cm}$ long magnet array, including four pieces of magnets was installed in the observation pipe. The flow system was run for 16 days to minimize instabilities caused by the compaction of the filling sand. After stabilization, the discharge rate through the observation pipe was $0.087 \mathrm{ml} / \mathrm{s}$.

A total of $1.3 \mathrm{~L}$ of nZVI slurry consisting of approximately $11.1 \mathrm{~g}$ of nZVI particles was released into the injection pipe, and then water was continuously injected to stabilize the flow field throughout the laboratory test. Immediately after the tracer injection, most of the nZVI slurry was observed to move downward to the bottom. Only a tiny amount, approximately $31 \mathrm{ml}$, migrated into the permeable conduit in the first $6 \mathrm{~min}$.
The fluid in the upper part of the pipe turned from opaque to translucent, while the fluid at the bottom turned dark. Such a phenomenon suggested the occurrence of settlement of most dark-colored nZVI particles at the bottom of the injection pipe. An interface was formed between the supernatant and the subnatant near the bottom. In addition, another interface formed between the diluted brown-colored PEI slurry and the follow-up fresh water at $58 \mathrm{~cm}$ above the bottom approximately $40 \mathrm{~min}$ after the injection. The interface slowly descended due to the flow of the slurry into the permeable conduit and settled at $24.7 \mathrm{~cm}$ above the bottom and just below the permeable conduit at $490 \mathrm{~min}$. It remained at this level during the following 6 months until the end of the laboratory test. Most nZVI particles formed chain-like micrometer-size clusters and deposited at the bottom of the injection pipe, and they remained as zero-valent irons even 6 months later, as shown in the inset of Fig. 1a.

A brown-colored viscous fluid was observed to reach the observation pipe approximately $35 \mathrm{~min}$ after the injection. This was followed by a rapid increase in electrical conductivity at the observation pipe, suggesting the arrival of injected nZVI slurry. The arriving fluid immediately was observed to move spirally downward to the bottom of the observation pipe due to the density effect. With increasing amounts of nZVI slurry, an interface between the slurry and fresh water appeared in the observation pipe. The interface rose slowly up to $24.7 \mathrm{~cm}$ above the bottom, as shown in Fig. 1a.

The magnet array was retrieved 4 days later to examine the weight distribution of nZVI particles attracted to the four

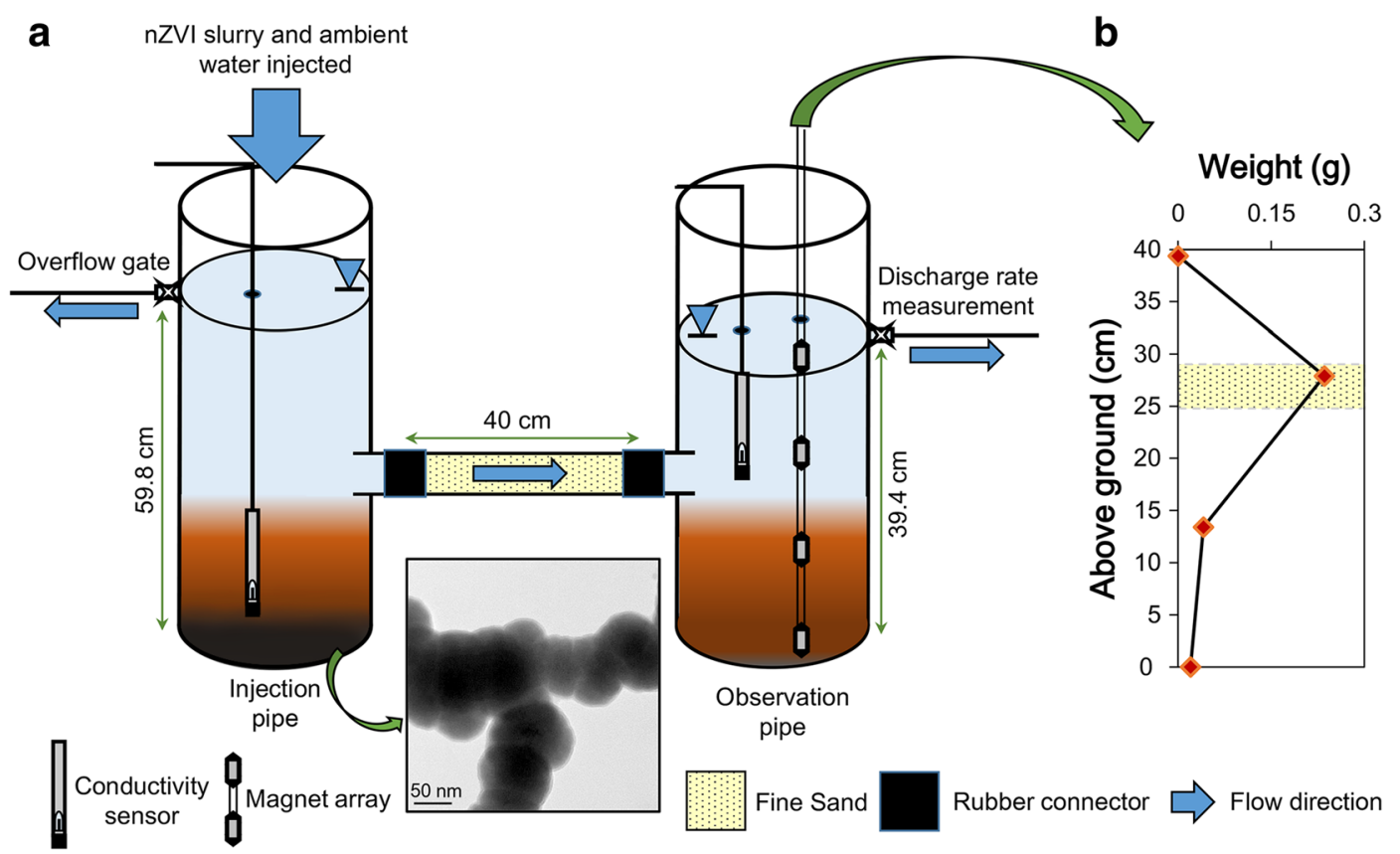

Fig. 1 Laboratory system for the nZVI tracer test. a Schematic diagram of test results 4 days after the injection of nZVI slurry. The inset shows a transmission electron microscopy (TEM) image of chain-like aggregated
nZVI particles. b Weight profile of nZVI particles attracted to the magnet array in the observation pipe 
separate magnets. The total weight of attracted nZVI particles was $0.2963 \mathrm{~g}$ and the mass recovery was approximately $2.67 \%$ of the injected weight of nZVI particles (Fig. 1b). It was noted that most of the accumulated nZVI particles, approximately $0.2356 \mathrm{~g}$, were attracted to the magnet closest to the permeable conduit located at $27.9 \mathrm{~cm}$ above the bottom. The nZVI particles were also found on other magnets, but the accumulated weight decreased significantly with increasing distance from the conduit.

Laboratory test results indicated that the magnet array is a useful device for detecting the incoming nZVI particles. However, most of the nZVI particles settled at the bottom of the injection pipe, reducing the mass recovery rate; therefore, in the field test, a sealed well was used for the tracer injection to limit the flow of the nZVI slurry to a narrow permeable segment. Compared with the injection in an open borehole, this approach can reduce the space below the connected fractures in the injection well and prevent the injected nZVI particles from settling to the bottom of injection well, improving the mass recovery of the nZVI tracer in the observation well.

\section{Field experiments}

\section{Experimental wells}

At the Heshe Experimental Forest of National Taiwan University in central Taiwan, a hydrogeological research station was established in fractured rock. The station covers an area of about $200 \mathrm{~m}^{2}$ near the bank of the Chenyoulan River. It is located $775 \mathrm{~m}$ above sea level in the pediment area of Wangma Mountain. Groundwater flows to the east with a mean gradient of 0.01 approximately under natural conditions.

Ten wells were drilled on site to conduct various hydrogeological studies in fractured rock (Wang et al. 2015). Of these, two experimental wells, W4 and W6, were used for this study. The distance between the two wells is $2.57 \mathrm{~m}$. The core logging indicated that the colluvial overburden is underlain by dark-gray shale and siltstone (Fig. 2). The overburden, extending from the surface to $18-19.5 \mathrm{~m}$ in depth, is primarily composed of unconsolidated sand and rock debris. The water table was approximately $9 \mathrm{~m}$ below the ground surface. W4 is a 45-m deep well cased and sealed from the surface to the depth of $21.5 \mathrm{~m}$, and screened with a $10.16-\mathrm{cm}$ diameter slotted screen from the depth of $21.5-45 \mathrm{~m}$. W6 is a $35-\mathrm{m}$ deep well cased to the depth of $21.5 \mathrm{~m}$ and open below. Before the tracer tests, a $2.8-\mathrm{cm}$ diameter tubing screened at the depth between 31 and $32.5 \mathrm{~m}$ was inserted into injection well $\mathrm{W} 6$.

\section{Preliminary field tests}

Two hydraulic tests were performed to investigate the hydraulic connectivity between W4 and W6 (Fig. S1 of the electronic

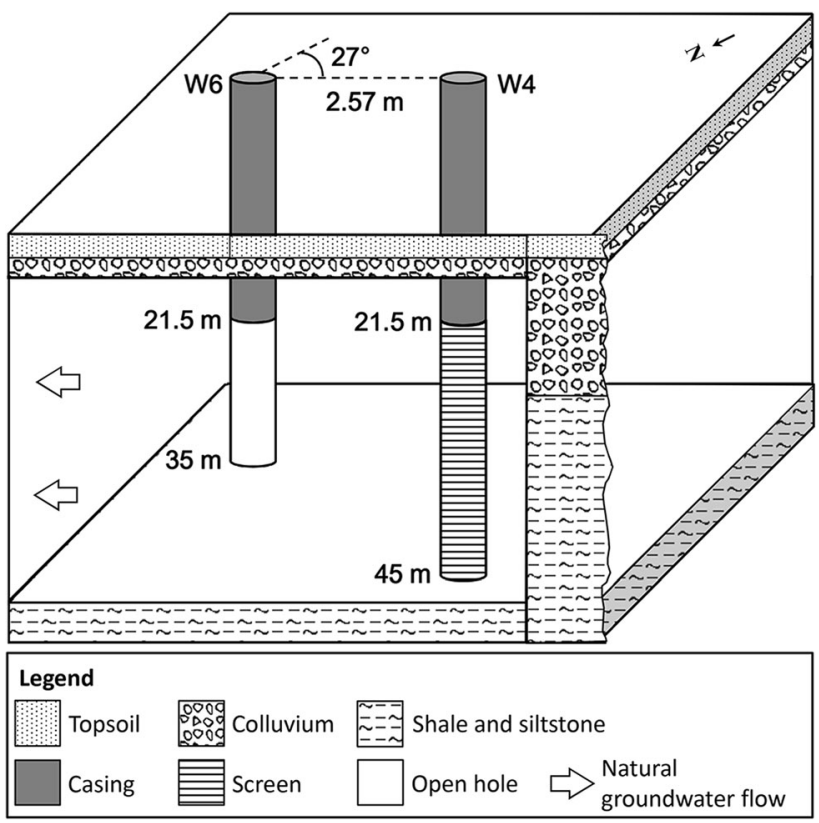

Fig. 2 Experimental wells and their geometric characteristics

supplementary material (ESM); see the ESM for detailed information of hydraulic tests and heat-pulse flowmeter tests). The results revealed hydraulic connectivity between the two wells. Then flowmeter tests were conducted to characterize the vertical distribution of permeable zones for locating the screened depth of the injection well. According to flowmeter measurements, the transmissivity in each $25-\mathrm{cm}$ section varied with depth (Fig. S2 of the ESM). Two permeable zones were identified respectively at depths of $23.5-24$ and $28-29 \mathrm{~m}$ in well W4. In well W6, three permeable zones were located respectively at depths of 24-25, 29.5-29.75 and 33-33.5 m (Fig. S3 of the ESM); the most permeable one was located at 33-33.5 m.

Results of the hydraulic tests suggested that wells W4 and W6 were hydraulically connected by permeable fractures. The most permeable zone at the depth of 33-33.5 $\mathrm{m}$ in W6 was chosen to conduct further field testing. A tubing screen was designed to be placed at a depth between 32 and $33.5 \mathrm{~m}$ in well W6. A sand pack was placed around the screened section and a $50-\mathrm{cm}$ thick bentonite plug was used for sealing the annular space above and below the sand pack to prevent groundwater from entering through nearby fractures. (Fig. S3 of the ESM). After the sealing of W6, a third hydraulic test was performed to re-examine the hydraulic connectivity between wells W4 and W6 (Fig. S1c of the ESM). The results showed that a hydraulic connection between $\mathrm{W} 4$ and W6 was still present through the $1.5-\mathrm{m}$ screened section in W6.

\section{Tracer tests}

Tracer tests were designed to investigate fracture flow paths between the wells, particularly the position of incoming 
tracers in the observation well. W6 was designated the injection well and W4 the observation well. Before the tracer tests, well W4 was pumped to reduce fine particles in the borehole and rock fractures. When an electrical conductivity sensor was placed in W6, the measured depth of the bottom hole was $32.5 \mathrm{~m}$, indicating the well W6 was actually screened from 31 to $32.5 \mathrm{~m}$, instead of the designed depth of 32-33.5 m. In W6, the transmissivity at the actual screened depth was smaller than that at the designed depth (Fig. S3 of the ESM); however, the third hydraulic test indicated that W4 and W6 were still connected despite misplacing the screened section in W6; thus, the two wells could be used for the saline and nZVI tracer tests.

In conformity with the measured depth of permeable zones by the flowmeter, an electrical conductivity sensor was placed at the depth of $29 \mathrm{~m}$ in $\mathrm{W} 6$, and two other sensors were installed respectively at the depths of 24 and $28.5 \mathrm{~m}$ in W4. Before the nZVI tracer test, a magnet array was placed between the depths of 23 and $43 \mathrm{~m}$ to detect where and how nZVI particles were attracted in W4. A forced gradient with a divergent flow field was used to conduct the tracer tests. A schematic diagram of the tracer test setting is shown in Fig. 3.

\section{Saline tracer test}

A saline solution was prepared by dissolving $1 \mathrm{~kg}$ of salt $(\mathrm{NaCl})$ in $20 \mathrm{~L}$ of water. The saline solution and water from a distant well were mixed and injected into W6 at a rate of

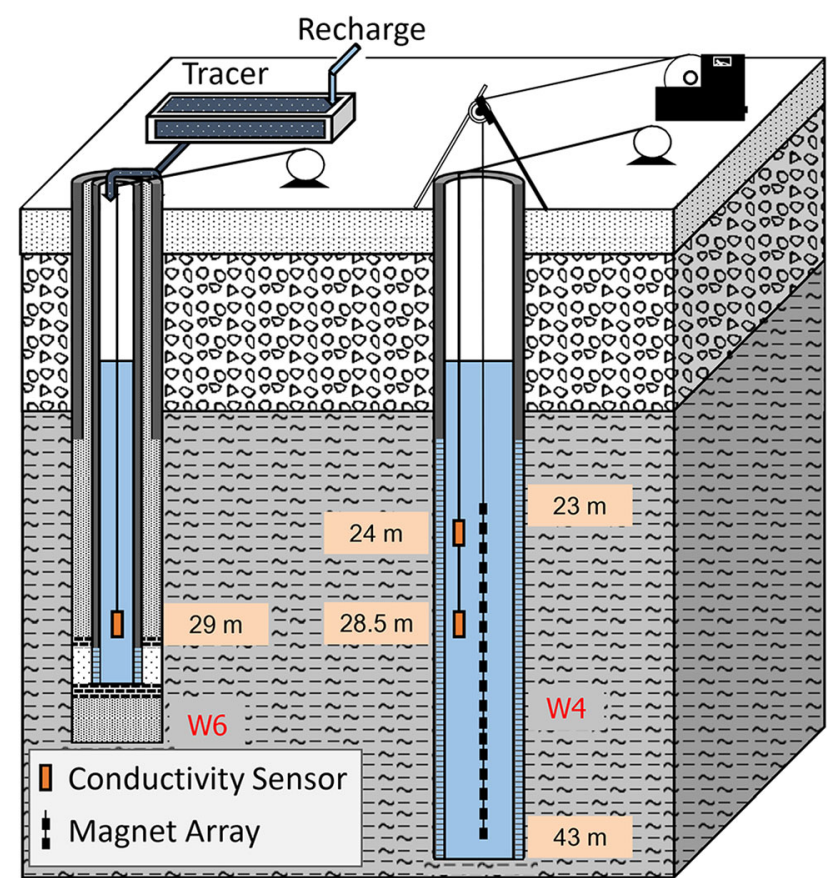

Fig. 3 Schematic diagram of the setting for the two tracer tests, including the saline tracer test and nZVI tracer test, in the field. Only in W4 (the observation well) was a 20 -m magnet array installed during the nZVI tracer test
$40 \mathrm{ml} / \mathrm{s}$ for about $9 \mathrm{~min}$. This was followed immediately by continuously injecting ambient water at a constant rate to maintain a constant head with an overflow condition throughout the test.

Before the injection, the background electrical conductivity in $\mathrm{W} 6$ was $650 \mu \mathrm{S} / \mathrm{cm}$ (Fig. 4a); however, 5 min into injection, the electrical conductivity at $29 \mathrm{~m}$ began to increase sharply, rising up to $60,190 \mu \mathrm{S} / \mathrm{cm}$ at $6 \mathrm{~min}$. Thereafter it was steady for about a minute and then dropped precipitously to $1,450 \mu \mathrm{S} / \mathrm{cm}$ at $14 \mathrm{~min}$; the pulse for the rise and fall lasted for approximately $10 \mathrm{~min}$.

Electrical conductivity at $24 \mathrm{~m}$ in the observation well was about $600-620 \mu \mathrm{S} / \mathrm{cm}$ throughout the test (Fig. 4b). In contrast, electrical conductivity at $28.5 \mathrm{~m}$ started to increase $9 \mathrm{~min}$ after tracer injection. It peaked at $17,389 \mu \mathrm{S} / \mathrm{cm}$ at $13 \mathrm{~min}$ and then declined to $650 \mu \mathrm{S} / \mathrm{cm}$ by the end of tracer test. The duration of the breakthrough curve was approximately $41 \mathrm{~min}$. The dispersion of saline solution was evident even though the horizontal distance was only $2.57 \mathrm{~m}$ between the wells. The test results indicated that the arrival of saline tracer in W4 through permeable fractures from W6; however, it was difficult to identify the actual positions of the permeable connected fractures in W4.

\section{nZVI tracer test}

Before the nZVI tracer test, $9 \mathrm{~L}$ of slurry consisting of approximately $77 \mathrm{~g}$ of nZVI particles was synthesized in the laboratory. The nZVI slurry was released into $\mathrm{W} 6$ at a rate of $37 \mathrm{ml} / \mathrm{s}$ for about $4 \mathrm{~min}$. Then ambient water was injected at a constant rate into the wellhead with an overflow condition to maintain a constant head throughout the test.

Electrical conductivity at $29 \mathrm{~m}$ in $\mathrm{W} 6$ was around $660 \mu \mathrm{S} / \mathrm{cm}$ before the nZVI slurry was injected (Fig. 5a), but declined to $380 \mu \mathrm{S} / \mathrm{cm}$ in $5 \mathrm{~min}$ before abruptly rising to $2,500 \mu \mathrm{S} / \mathrm{cm} 7 \mathrm{~min}$ after the nZVI slurry had been injected. As the electrical conductivity was $360 \mu \mathrm{S} / \mathrm{cm}$ at the depth of $12 \mathrm{~m}$ and $660 \mu \mathrm{S} / \mathrm{cm}$ at the depth of $29 \mathrm{~m}$ prior to the test, the initial decrease in electrical conductivity was likely caused by the downward flow of shallow stagnant water in W6. The conductivity decrease was followed by a rapid increase due to passage of the nZVI slurry. After all the nZVI slurry had migrated into the permeable fracture at $10 \mathrm{~min}$, electrical conductivity in the injection well varied between 560 and $610 \mu \mathrm{S} /$ $\mathrm{cm}$ because of the follow-up injection of ambient water.

In W4, electrical conductivity was recorded throughout the tracer test at 24 and $28.5-\mathrm{m}$ depths (Fig. 5b). At $24 \mathrm{~m}$, it was $610-620 \mu \mathrm{S} / \mathrm{cm}$ for the first $98 \mathrm{~min}$ after the injection. Subsequently, it slowly decreased and stabilized at $570 \mu \mathrm{S} /$ $\mathrm{cm}$ through the end of the tracer test. This result indicated that the nZVI slurry did not migrate upward to $24 \mathrm{~m}$ in the observation well. On the contrary, the electrical conductivity at $28.5 \mathrm{~m}$ depth in $\mathrm{W} 4$ started to increase $1.7 \mathrm{~min}$ after the 
Fig. 4 Changes in electrical conductivity during the saline tracer test. a Time series of electrical conductivity recorded at the depth of $29 \mathrm{~m}$ in injection well W6. b Time series of electrical conductivity recorded at depths of 24 and $28.5 \mathrm{~m}$, respectively, in observation well $W 4$. The horizontal axes are the elapsed time after the saline tracer injection

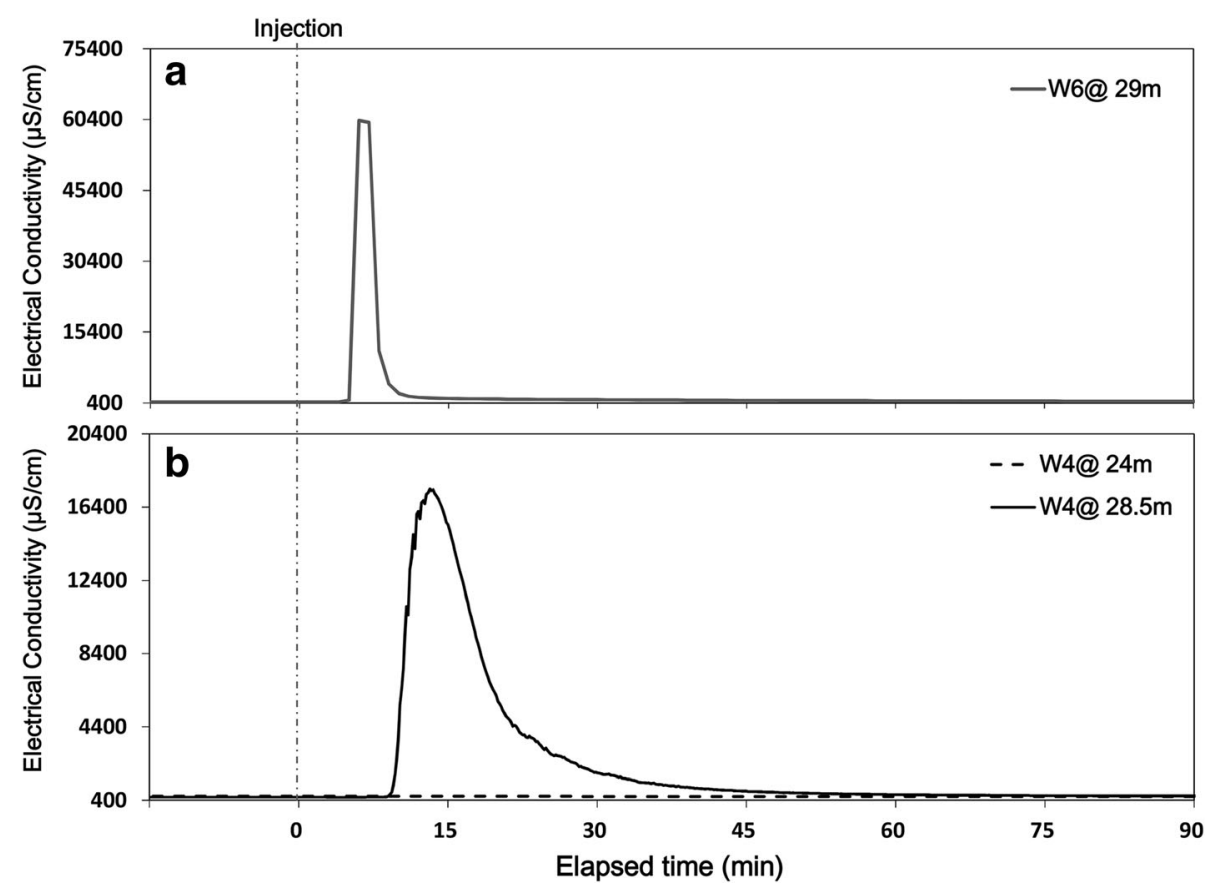

injection, and reached a small peak of $639 \mu \mathrm{S} / \mathrm{cm}$ at $9 \mathrm{~min}$. The small peak was likely caused by the inflow of formation water or deep stagnant well water $(660 \mu \mathrm{S} / \mathrm{cm})$ in $\mathrm{W} 6$. Immediately after, the electrical conductivity declined to $563 \mu \mathrm{S} / \mathrm{cm}$ and then rose sharply $11.5 \mathrm{~min}$ after the injection. These conductivity changes were associated with the arrival of well water in W6. The second peak of electrical conductivity was about $985 \mu \mathrm{S} / \mathrm{cm}$, which was much higher than the ambient electrical conductivity $(560-660 \mu \mathrm{S} / \mathrm{cm})$, indicating the arrival of the nZVI slurry. This was followed by a decrease in electrical conductivity to $483 \mu \mathrm{S} / \mathrm{cm}$ at $21 \mathrm{~min}$. Then the electrical conductivity increased again to the background level and stayed in the range of 560-620 $\mathrm{SS} / \mathrm{cm}$ until the end of tracer test.

Before the nZVI tracer injection, a neodymium magnet was placed downhole in the wells W4 and W6 and then retrieved to examine the amount of magnetic minerals in the well water. The result did not show any magnetic mineral attracted to the magnet in the two wells. After the completion of the nZVI tracer test, the magnet array assembly was retrieved and examined for the depth and weight of nZVI particles attached to
Fig. 5 Changes in electrical conductivity during the nZVI tracer test. a Time series of electrical conductivity recorded at the depth of $29 \mathrm{~m}$ in injection well W6. b Time series of electrical conductivity recorded at depths of 24 and $28.5 \mathrm{~m}$, respectively, in observation well W4. The horizontal axes are the elapsed time after the nZVI tracer injection
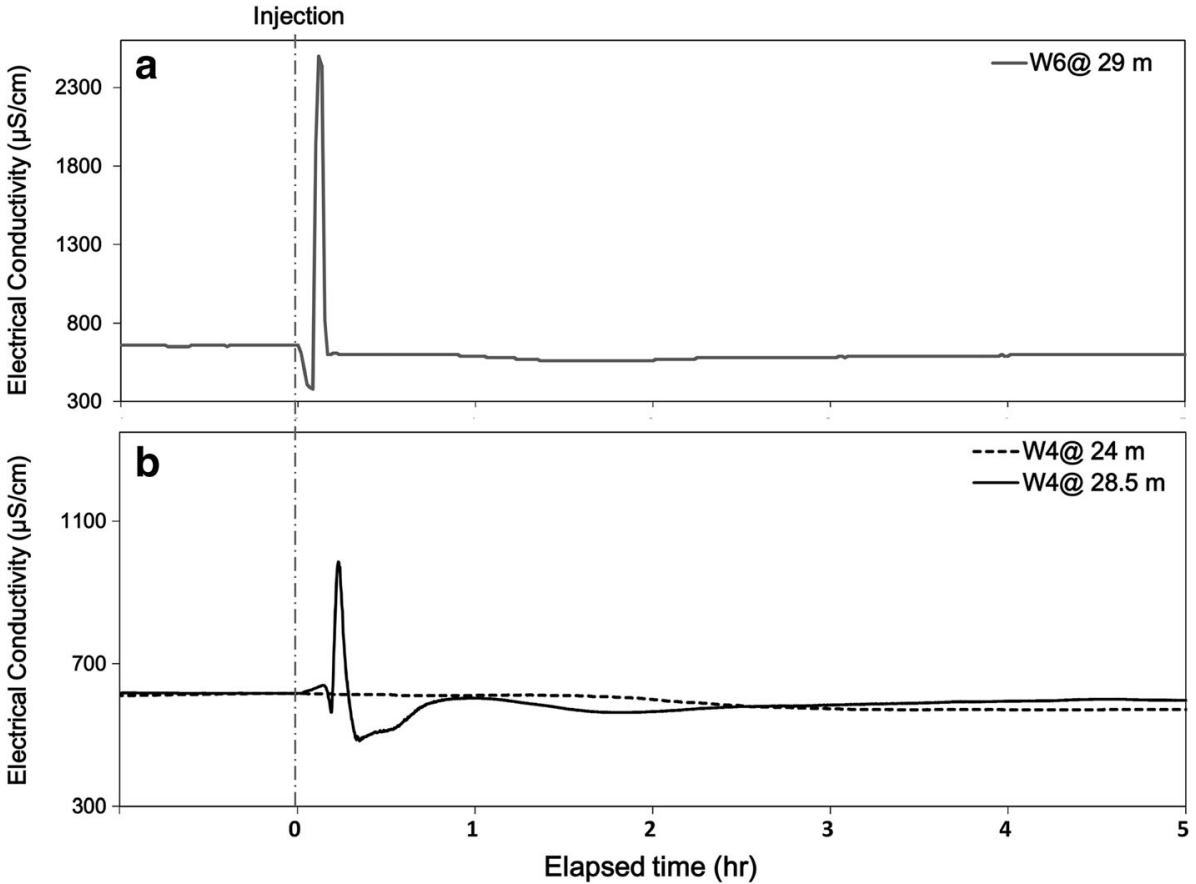
the magnets. The weight of accumulated nZVI particles on the separate magnets ranged from 0.011 to $0.317 \mathrm{~g}$ (Fig. 6). The total weight of attached nZVI particles was $5.773 \mathrm{~g}$, which was approximately $7.5 \%$ of the injected nZVI particles. The distribution of accumulated nZVI particles on the magnet array ranged between depths of 27 and $43 \mathrm{~m}$. The weight profile of accumulated nZVI particles peaked at $28.6 \mathrm{~m}$, which is consistent with the large changes of electrical conductivity observed there. The laboratory test indicated that the accumulated weight of nZVI particles on a magnet depends on the distance between the flow inlet and the magnet; hence, the weight distribution as a result of the tracer test suggested that the flow inlet of the nZVI slurry was likely to be located between 28 and $29 \mathrm{~m}$ in W4. The measured depth of flow inlet agrees with that of a highly permeable zone obtained from heat-pulse flowmeter measurements (Fig. 6).

\section{Flow paths between the wells}

According to the flowmeter measurements in W6, the most permeable zone was between 33 and $33.5 \mathrm{~m}$; however, the tubing was actually screened between 31 and $32.5 \mathrm{~m}$ in depth (Fig. S3 of the ESM). Although the section transmissivity of the $1.5-\mathrm{m}$ screened section was relatively small, the nZVI

Fig. 6 Weight profile of $n Z V I$ particles attracted to the magnet array, section transmissivity from flowmeter measurements, and rock core image in observation well W4. Each point on the plot represents the weight of nZVI particles attracted to a piece of magnet. Each section is $25-\mathrm{cm}$ thick tracer test revealed that fractures between 28 and $29 \mathrm{~m}$ in W4 and the screened section between 31 and $32.5 \mathrm{~m}$ in W6 were hydraulically connected (Fig. 6).

Because the permeable zone between 33 and $33.5 \mathrm{~m}$ in W6 was sealed, the nearby less permeable fractures became alternative flow paths. By integrating the flowmeter measurement data with the nZVI tracer test results, the tracer must have migrated through a "subordinate permeable zone" adjacent to the screened section in W6, and then passed through the "dominant permeable zone" into W4 (Fig. 7). The results suggested that the main permeable conduit might have a hydraulic connection with nearby subordinate fractures. When the main permeable conduit was sealed by cement or sediment, these subordinate fractures might become the alternative flow paths. In other words, connecting fractures are not necessarily only one but could easily be a network providing different paths.

\section{Numerical simulation of tracer tests}

\section{Simulation of the saline tracer test}

A two-dimensional groundwater flow and solute transport model was developed using MODFLOW-2005 (Harbaugh

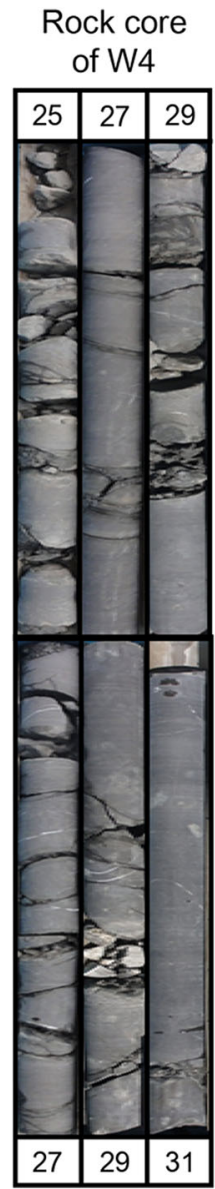

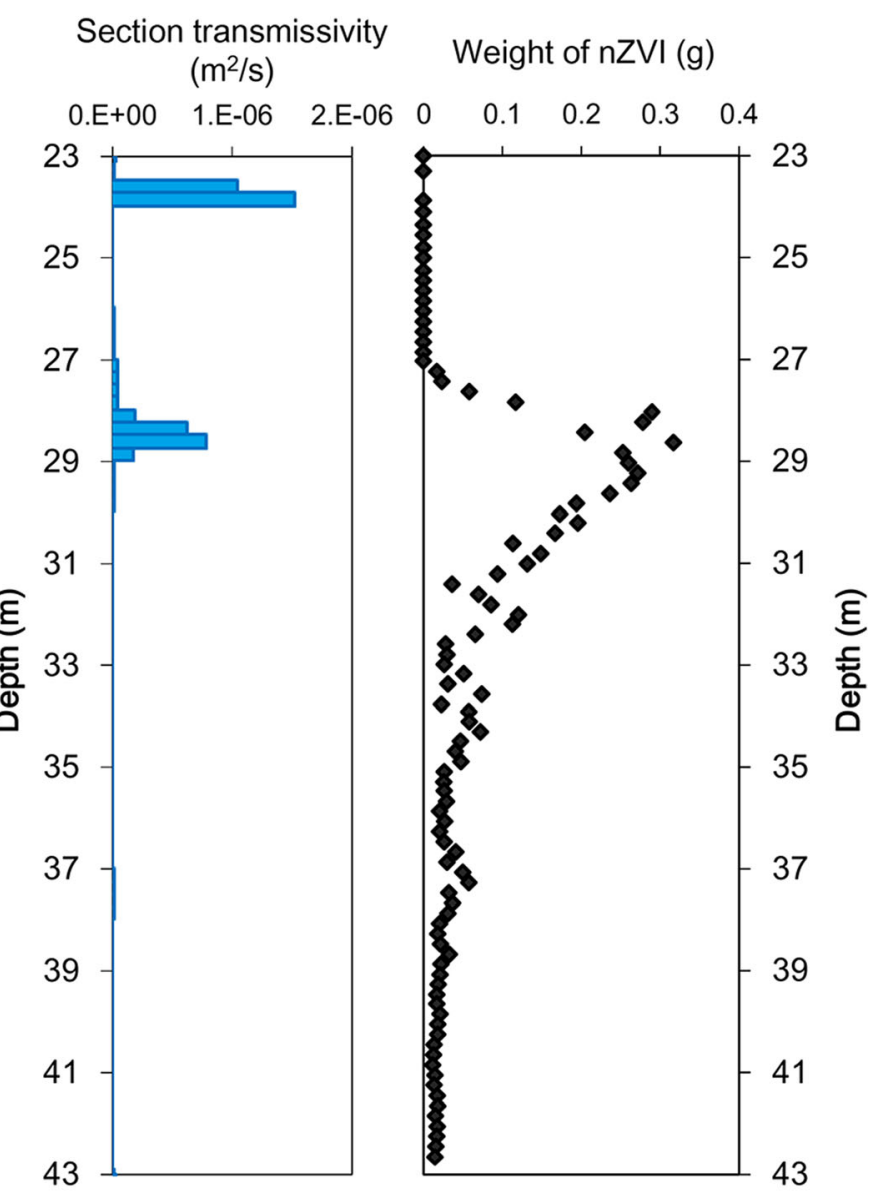




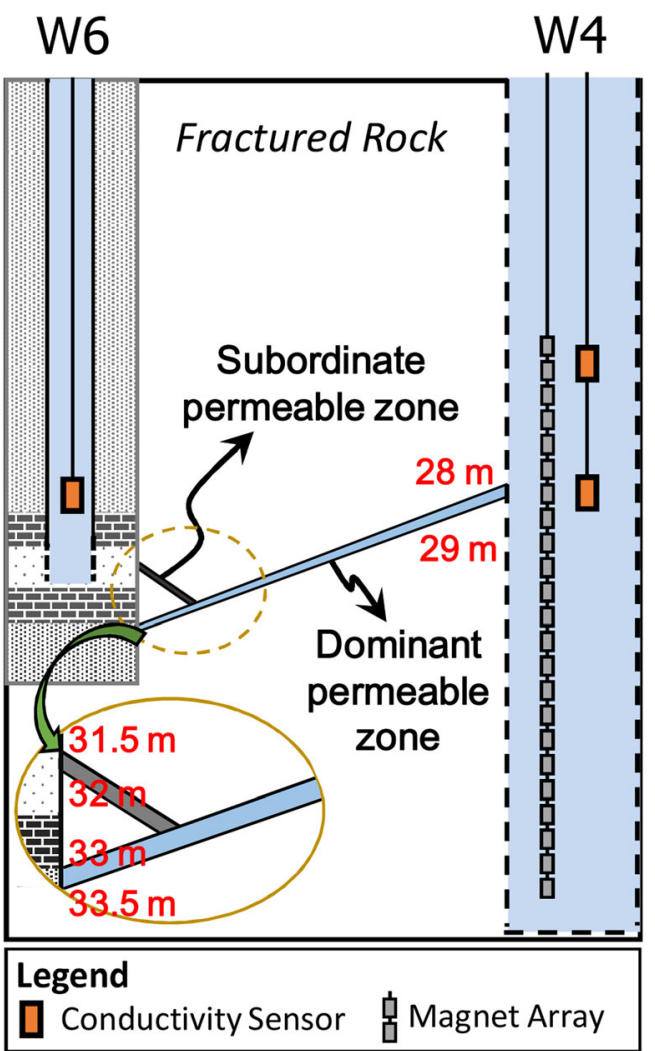

Fig. 7 Schematic diagram of dominant and subordinate permeable fracture zones connected between wells $W 6$ and $W 4$

2005) and MT3DMS (Zheng and Wang 1999). The model was initially used to simulate the saline tracer test (see the ESM for the spatial discretization and boundary conditions of groundwater flow and solute transport model). The recorded saline concentrations during the test were adopted to calibrate the model. The parameters, including the hydraulic conductivities of two permeable zones as well as dispersivities, were specified to produce the best match between the observed and calculated concentrations during the saline tracer test.

The empirical relationship between the electrical conductivity and the concentration of the saline solution was obtained in the laboratory. Hence, fluid conductivities at $29 \mathrm{~m}$ in W6 (Fig. 4a) were converted to saline concentrations at the release point (Fig. S4 of the ESM). The breakthrough curve was shown by a plot of normalized concentrations $\left(\mathrm{C} / \mathrm{C}_{0}\right)$ versus elapsed time. $\mathrm{C} / \mathrm{C}_{0}$ is the ratio of the measured concentration at the observation point in well W4 to the maximum injected concentration. PEST (Doherty 2015), an automatic software for parameter estimation, was used to calibrate the model. The simulated and the observed breakthrough curves of the saline tracer test match with each other (Fig. 8). The calibrated hydraulic conductivities of dominate and subordinate permeable zones are $1.046 \times 10^{-2}$ and $1.517 \times 10^{-3} \mathrm{~m} / \mathrm{s}$, respectively. The calibrated longitudinal dispersivity is $0.124 \mathrm{~m}$, while the transverse dispersivity is $0.0124 \mathrm{~m}$ (see the ESM for the

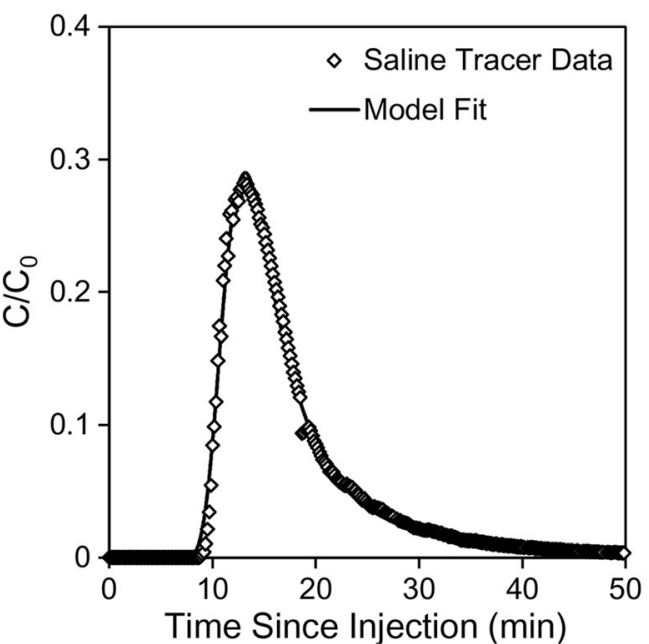

Fig. 8 Comparison of the calculated and observed breakthrough curves at the observation point during the saline tracer test. The breakthrough curve is plotted as normalized concentration $\left(C / C_{0}\right)$ of saline solution against elapsed time since the injection. $\mathrm{C} / \mathrm{C}_{0}$ is the ratio of the concentration at the depth of $28.5 \mathrm{~m}$ in observation well $\mathrm{W} 4$ to the maximum concentration in injection well W6

uncertainty and sensitivity analysis of model output). Based on the flowmeter measurement results, the transmissivities of the dominant and subordinate permeable zones in W6 are $1.73 \times 10^{-6}$ and $2.51 \times 10^{-7} \mathrm{~m}^{2} / \mathrm{s}$, respectively. Thus, the estimated effective aperture of the fracture, calculated by the transmissivities of the permeable zones divided by the identified hydraulic conductivities, is about $0.16-0.17 \mathrm{~mm}$.

\section{Simulation of the nZVI tracer test}

After calibrating the numerical model, the model was used to simulate the nZVI tracer test. All geological parameters were the same in both saline and nZVI tracer tests to maintain the same flow fields. Specified head boundaries were set to the hydraulic heads measured in wells W4 and W6 during the nZVI tracer test. Electrical conductivity is assumed to vary linearly with the concentrations of the nZVI slurry-for comparison, the simulated concentration was converted to electrical conductivity (EC). Both the simulated and observed electrical conductivities were normalized by the maximum initial electrical conductivity $\left(\mathrm{EC}_{0}\right)$.

Simulated results indicate that the nZVI slurry passed $28.5 \mathrm{~m}$ in W4 from 11 to $24 \mathrm{~min}$ (Fig. 9a). While the simulated maximum electrical conductivity of the nZVI slurry occurred at $14.9 \mathrm{~min}$, the maximum electrical conductivity in W4 was recorded at $13.7 \mathrm{~min}$ (Fig. 9b). The simulated tracer breakthrough curve cannot match with the observed data of the nZVI tracer test. The inconsistency is likely caused by the difference in fluid velocity and dispersivity between the nZVI slurry and the saline solution. The difference in velocity can be attributed to different viscosity, density and interference between the slurry and the solution. The difference in 

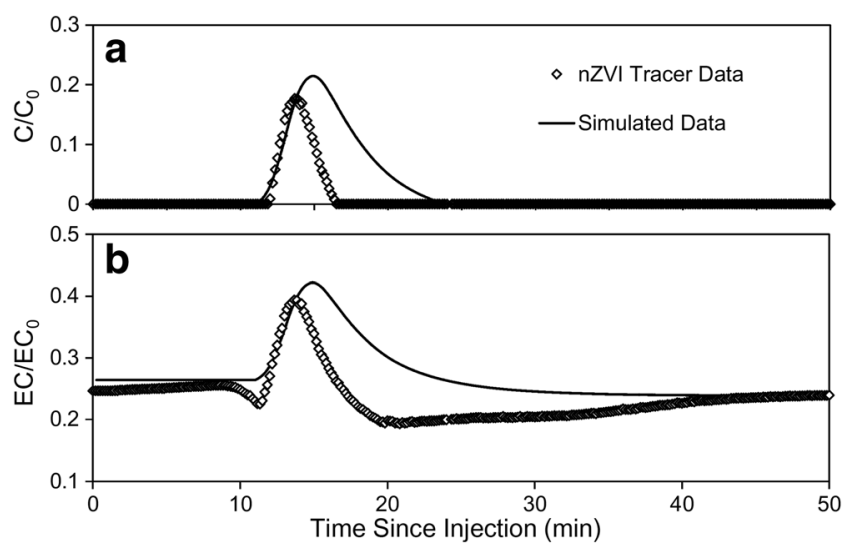

Fig. 9 Breakthrough curves at the observation point during the nZVI tracer test. a The calculated $\mathrm{C} / \mathrm{C}_{0}$ of the nZVI slurry is compared against the observed $\mathrm{C} / \mathrm{C}_{0}$ versus elapsed time since the injection. b The calculated $\mathrm{EC} / \mathrm{EC}_{0}$ of the nZVI slurry is compared against the observed $\mathrm{EC} / \mathrm{EC}_{0}$ versus elapsed time since the injection. $E C$ is the electrical conductivity at the depth of $28.5 \mathrm{~m}$ in observation well W4, and $E C_{0}$ is the maximum electrical conductivity in injection well W6

velocity and dispersivity can also be induced by elevated velocity and degraded dispersion coefficient due to larger size of nZVI particles than that of solutes (James and Chrysikopoulos 2003).

\section{Discussion and conclusions}

\section{Discussion}

By comparing the two breakthrough curves recorded at the depth of $28.5 \mathrm{~m}$ in W4 (Figs. $4 \mathrm{~b}$ and $5 \mathrm{~b}$ ), one can see the nZVI tracer less dispersive than the saline tracer. The variance is attributed to the difference in migration between solute and colloid with solid particles. During the tracer injection, the nZVI slurry is diluted by the well water, reducing the stability of the colloidal system. The nZVI particles tend to form chainlike aggregates that can lead to the formation of micrometersized particles (Phenrat et al. 2007). As the aggregates of large size cannot pass through small pores, they tend to migrate through larger pores in the connected fractures. The effective particle velocity is elevated, while the overall particle dispersion is degraded in a fracture (James and Chrysikopoulos 2003); therefore, the pulse change in electrical conductivity caused by the nZVI tracer migration is faster, but less dispersive than that caused by the saline tracer.

Tracer test results indicated that nZVI particles attracted to the magnet array provided a direct evidence of a preferential flow path to the observation well. The weight profile of nZVI particles peaked at $28.6 \mathrm{~m}$ in W4 (Fig. 6). As a result of a magnetic attraction force of neodymium magnet, most of nZVI particles of the incoming slurry were attracted to the magnets near the entrance, particularly the segment between 28 and $29 \mathrm{~m}$. A small amount was observed below the segment due to gravity sedimentation. Only a tiny amount was carried upward possibly cause by the increasing hydraulic head in W4 during the injection process. Based on the monitoring data at observation well W4, the well water level increased $1.08 \mathrm{~m}$ in $35 \mathrm{~min}$ after the injection, and then remained steady at this level till the end of tracer test. Such an increase was expected to induce the upward flow at W4 during the first $35 \mathrm{~min}$. Generally the mass of nZVI particles captured by the magnets decreased with increasing distance from the entrance (Fig. 6), similar to the observations in the laboratory test (Fig. 1b); hence, the mass profile of attracted nZVI particles can be used to locate the position of connected permeable fracture zones.

Some smaller peaks in the weight profile were found below $29 \mathrm{~m}$ in depth (Fig. 6). These peaks are attributed to a nonuniform downward migration of the nZVI slurry. In the laboratory test, the nZVI slurry was observed to migrate spirally downward to the bottom in the observation pipe. The nZVI particles would be randomly attracted to the magnets while moving downward in the observation well, resulting in a nonlinear decaying weight profile. The smaller peaks are also possibly caused by the inflow of nZVI slurry through less permeable connected fractures.

The total mass of accumulated nZVI particles on the magnet array was $5.773 \mathrm{~g}$. The total mass of injected nZVI particles was $77 \mathrm{~g}$; thus, the mass recovery rate in the nZVI tracer test was approximately $7.5 \%$. In a two-dimensional homogeneous formation, the injected tracer is anticipated to migrate radially from an injection well. The distance between the injection well and the observation well is $2.57 \mathrm{~m}$. As the circumference of the divergent flow is $16.14 \mathrm{~m}$ and the diameter of the observation well is $10.16 \mathrm{~cm}$, the theoretical mass recovery rate would only be $0.63 \%$. Clearly, the actual mass recovery from the test is more than ten times larger than the theoretical recovery. Such a contrast suggests that transport through the permeable fracture zones is controlled by strong heterogeneity or channelized flow patterns in fractures. The outflow of injected nZVI particles through permeable fractures is largely confined to limited routes, including the one between the injection and observation wells.

As nZVI particles are non-conservative tracer, they may react with the ambient groundwater during the transport process, leading to the mass loss of nano-iron particles. The most important concern is the oxidation of nZVI particles. As the laboratory flow system was carried out in an aerobic environment, most nZVI particles formed chain-like micrometersized clusters and remained as zero-valent irons even 6 months after. In the field, the nZVI tracer test was conducted in approximately $5 \mathrm{~h}$, and thus the mass loss of nZVI particles due to the chemical reaction is not a major concern in this study.

The clogging of nZVI particles in rock fractures can be influenced by mechanical entrapment, including attachment, filtration and straining. The dominant retention mechanism 
may vary with the specific discharge in a fracture (Crane and Moore 1984; Rodrigues et al. 2013). Generally smaller specific discharges (slow flow velocities) result in smaller shear forces, thereby leading to attachment. In the field test of this study, the specific discharge is large due to the injection, and thus the attachment of nZVI particles is relatively small; however, filtration and straining in the fracture may cause clogging of fractures.

Compared with other investigation approaches in fractured rock, the nZVI tracer test did provide more direct and quantitative information such as the maximum attracted mass to the magnets, for delineating the position of tracer inlet (connecting fracture) in the observation well. The position is consistent with the result of saline tracer test and the heatpulse flowmeter measurements. However, the density effect, clogging of fractures and chemical reactions of nZVI particles may involve in the transport processes, leading to the uncertainty in the delineation of tracer inlet and limiting the application of using nZVI tracers. Further experiments are needed to examine the application and limitation of the nZVI tracer test.

\section{Conclusions}

A novel approach of an nZVI tracer test was developed to characterize the preferential flow paths between a screened well and an open hole. By using a magnet array assembly, the distribution of absorbed nZVI particles can be used to locate the depth of incoming tracer in the observation well, providing quantitative approach for delineating connecting fractures. Although the most permeable zone in the injection well was sealed due to misplacing the screened section, the results of both the nZVI tracer test and the saline tracer test revealed that the main permeable conduit might have a hydraulic connection through other nearby subordinate fractures. In other words, once part of the main permeable conduit is sealed by cement or sediments, these subordinate fractures might become the alternative flow paths. This phenomenon was an interesting finding in addition to the delineation of connected fractures. The mass recovery rate of nZVI particles was successfully enhanced by hydraulically isolating a permeable segment in the injection well; however, the actual recovery rate was much higher than the well-dispersed theoretical recovery rate, suggesting the presence of strong heterogeneity or channelized flow patterns in rock fractures. This study has demonstrated that an nZVI tracer test could be a promising approach for characterizing fracture flow paths.

Acknowledgements The authors would like to thank the Central Geological Survey, Taiwan Power Co., Industrial Technology Research Institute and Sinotech Inc. for their technical assistance in the field. The authors also appreciate the reviews by Jim Yeh and four anonymous reviewers. The study is supported by a research grant from the Ministry of Science and Technology of Taiwan (MOST 105-2116-M-002-023).
Open Access This article is distributed under the terms of the Creative Commons Attribution 4.0 International License (http:// creativecommons.org/licenses/by/4.0/), which permits unrestricted use, distribution, and reproduction in any medium, provided you give appropriate credit to the original author(s) and the source, provide a link to the Creative Commons license, and indicate if changes were made.

\section{References}

Banks EW, Shanafield MA, Cook PG (2014) Induced temperature gradients to examine groundwater flowpaths in open boreholes. Ground Water 52:943-951. doi:10.1111/gwat.12157

Barton CA, Zoback MD, Moos D (1995) Fluid-flow along potentially active faults in crystalline rock. Geology 23:683-686. doi:10.1130/ 0091-7613(1995)023<0683:Ffapaf $>2.3 . C o ; 2$

Bense VF, Read T, Bour O, Le Borgne T, Coleman T, Krause S, Chalari A, Mondanos M, Ciocca F, Selker JS (2016) Distributed temperature sensing as a downhole tool in hydrogeology. Water Resour Res 52: 9259-9273. doi:10.1002/2016wr018869

Berkowitz B (2002) Characterizing flow and transport in fractured geological media: a review. Adv Water Resour 25:861-884. doi:10. 1016/S0309-1708(02)00042-8

Braester C, Thunvik R (1984) Determination of formation permeability by double-packer tests. J Hydrol 72:375-389. doi:10.1016/00221694(84)90090-8

Chuang PY, Chia Y, Liou YH, Teng MH, Liu CY, Lee TP (2016) Characterization of preferential flow paths between boreholes in fractured rock using a nanoscale zero-valent iron tracer test. Hydrogeol J 24:1651-1662. doi:10.1007/s10040-016-1426-7

Coleman TI, Parker BL, Maldaner CH, Mondanos MJ (2015) Groundwater flow characterization in a fractured bedrock aquifer using active DTS tests in sealed boreholes. J Hydrol 528:449-462. doi:10.1016/j.jhydrol.2015.06.061

Comba S, Sethi R (2009) Stabilization of highly concentrated suspensions of iron nanoparticles using shear-thinning gels of xanthan gum. Water Res 43:3717-3726. doi:10.1016/j.watres.2009.05.046

Crane SR, Moore JA (1984) Bacterial pollution of groundwater: a review. Water Air Soil Poll 22:67-83. doi:10.1007/Bf00587465

Doherty J (2015) Calibration and uncertainty analysis for complex environmental models. Watermark, Brisbane, Australia

Goon IY, Lai LMH, Lim M, Munroe P, Gooding JJ, Amal R (2009) Fabrication and dispersion of gold-shell-protected magnetite nanoparticles: systematic control using polyethyleneimine. Chem Mater 21:673-681. doi:10.1021/cm8025329

Hao Y, Yeh TC, Xiang J, Illman WA, Ando K, Hsu KC, Lee CH (2008) Hydraulic tomography for detecting fracture zone connectivity. Ground Water 46:183-192. doi:10.1111/j.1745-6584.2007.00388.x

Harbaugh AW (2005) MODFLOW-2005, the US geological survey modular ground-water model: the ground-water flow process. US Geological Survey, Reston, VA

James SC, Chrysikopoulos CV (2003) Effective velocity and effective dispersion coefficient for finite-sized particles flowing in a uniform fracture. J Colloid Interface Sci 263:288-295. doi:10.1016/S00219797(03)00254-6

Klepikova MV, Le Borgne T, Bour O, Gallagher K, Hochreutener R, Lavenant N (2014) Passive temperature tomography experiments to characterize transmissivity and connectivity of preferential flow paths in fractured media. J Hydrol 512:549-562. doi:10.1016/j. jhydrol.2014.03.018

Lapcevic PA, Novakowski KS, Sudicky EA (1999) The interpretation of a tracer experiment conducted in a single fracture under conditions of natural groundwater flow. Water Resour Res 35:2301-2312. doi: 10.1029/1999wr900143 
Lee TP, Chia YP, Chen JS, Chen HE, Liu CW (2012) Effects of free convection and friction on heat-pulse flowmeter measurement. J Hydrol 428:182-190. doi:10.1016/j.jhydrol.2012.02.001

Ma R, Zheng CM, Zachara JM, Tonkin M (2012) Utility of bromide and heat tracers for aquifer characterization affected by highly transient flow conditions. Water Resour Res 48. doi:10.1029/2011wr011281

Molz FJ, Boman GK, Young SC, Waldrop WR (1994) Borehole flowmeters: field application and data-analysis. J Hydrol 163:347-371. doi:10.1016/0022-1694(94)90148-1

Neuman SP (2005) Trends, prospects and challenges in quantifying flow and transport through fractured rocks. Hydrogeol J 13:124-147. doi: 10.1007/s10040-004-0397-2

Novakowski KS, Lapcevic PA (1994) Field measurement of radial solute transport in fractured rock. Water Resour Res 30:37-44. doi:10. 1029/93wr02401

Phenrat T, Saleh N, Sirk K, Tilton RD, Lowry GV (2007) Aggregation and sedimentation of aqueous nanoscale zerovalent iron dispersions. Environ Sci Technol 41:284-290. doi:10.1021/es061349a

Phenrat T, Saleh N, Sirk K, Kim HJ, Tilton RD, Lowry GV (2008) Stabilization of aqueous nanoscale zerovalent iron dispersions by anionic polyelectrolytes: adsorbed anionic polyelectrolyte layer properties and their effect on aggregation and sedimentation. $\mathrm{J}$ Nanopart Res 10:795-814. doi:10.1007/s11051-007-9315-6

Read T, Bour O, Bense V, Le Borgne T, Goderniaux P, Klepikova MV, Hochreutener R, Lavenant N, Boschero V (2013) Characterizing groundwater flow and heat transport in fractured rock using fiberoptic distributed temperature sensing. Geophys Res Lett 40:20552059. doi:10.1002/grl.50397

Read T, Bour O, Selker JS, Bense VF, Le Borgne T, Hochreutener R, Lavenant N (2014) Active-distributed temperature sensing to continuously quantify vertical flow in boreholes. Water Resour Res 50: 3706-3713. doi:10.1002/2014wr015273

Rodrigues SN, Dickson SE, Qu J (2013) Colloid retention mechanisms in single, saturated, variable-aperture fractures. Water Res 47:31-42. doi:10.1016/j.watres.2012.08.033

Sellwood SM, Bahr JM, Hart DJ (2016) Evaluation of a discrete-depth heat dissipation test for thermal characterization of the subsurface. Geol Soc Am Spec Pap 519:67-79. doi:10.1130/2016.2519(05)

Sharmeen R, Illman WA, Berg SJ, Yeh TCJ, Park YJ, Sudicky EA, Ando K (2012) Transient hydraulic tomography in a fractured dolostone: laboratory rock block experiments. Water Resour Res 48, W10532. doi: 10.1029/2012wr012216

Sidorov SN, Bronstein LM, Valetsky PM, Hartmann J, Colfen H, Schnablegger H, Antonietti M (1999) Stabilization of metal nanoparticles in aqueous medium by polyethyleneoxidepolyethyleneimine block copolymers. J Colloid Interface Sci 212: 197-211. doi:10.1006/jcis.1998.6035

Tiraferri A, Chen KL, Sethi R, Elimelech M (2008) Reduced aggregation and sedimentation of zero-valent iron nanoparticles in the presence of guar gum. J Colloid Interface Sci 324:71-79. doi:10.1016/j.jcis. 2008.04.064
Tsang CF, Hufschmied P, Hale FV (1990) Determination of fracture inflow parameters with a borehole fluid conductivity logging method. Water Resour Res 26:561-578. doi:10.1029/WR026i004p00561

Varanasi P, Fullana A, Sidhu S (2007) Remediation of PCB contaminated soils using iron nano-particles. Chemosphere 66:1031-1038. doi: 10.1016/j.chemosphere.2006.07.036

Wang CB, Zhang WX (1997) Synthesizing nanoscale iron particles for rapid and complete dechlorination of TCE and PCBs. Environ Sci Technol 31:2154-2156. doi:10.1021/es970039c

Wang XL, Zhou LZ, Ma YJ, Li X, Gu HC (2009) Control of aggregate size of polyethyleneimine-coated magnetic nanoparticles for magnetofection. Nano Res 2:365-372. doi:10.1007/s12274-0099035-6

Wang TT, Zhan SS, Huang TH (2015) Determining transmissivity of fracture sets with statistical significance using single-borehole hydraulic tests: methodology and implementation at Heshe well site in central Taiwan. Eng Geol 198:1-15. doi:10.1016/j.enggeo.2015.09. 006

Williams JH, Johnson CD (2000) Borehole-wall imaging with acoustic and optical televiewers for fractured-bedrock aquifer investigations. Seventh International Symposium on Borehole Geophysics for Minerals, Geotechnical, and Groundwater Applications, Houston, TX, October 2000, pp 43-53

Williams JH, Paillet FL (2002) Using flowmeter pulse tests to define hydraulic connections in the subsurface: a fractured shale example. J Hydrol 265:100-117. doi:10.1016/S0022-1694(02)00092-6

Williams DN, Gold KA, Holoman TRP, Ehrman SH, Wilson OC (2006) Surface modification of magnetic nanoparticles using gum arabic. $\mathrm{J}$ Nanopart Res 8:749-753. doi:10.1007/s11051-006-9084-7

Zha YY, Yeh TCJ, Mao DQ, Yang JZ, Lu WX (2014) Usefulness of flux measurements during hydraulic tomographic survey for mapping hydraulic conductivity distribution in a fractured medium. Adv Water Resour 71:162-176. doi:10.1016/j.advwatres.2014.06.008

Zha Y, Yeh T-CJ, Illman WA, Tanaka T, Bruines P, Onoe H, Saegusa H (2015) What does hydraulic tomography tell us about fractured geological media? A field study and synthetic experiments. J Hydrol 531:17-30. doi:10.1016/j.jhydrol.2015.06.013

Zha Y, Yeh TJ, Illman WA, Tanaka T, Bruines P, Onoe H, Saegusa H, Mao D, Takeuchi S, Wen JC (2016) An application of hydraulic tomography to a large-scale fractured granite site, Mizunami, Japan. Ground Water 54:793-804. doi:10.1111/gwat.12421

Zhao J (1998) Rock mass hydraulic conductivity of the Bukit Timah granite, Singapore. Eng Geol 50:211-216. doi:10.1016/S00137952(98)00021-0

Zheng C, Wang PP (1999) MT3DMS: a modular three-dimensional multispecies transport model for simulation of advection, dispersion, and chemical reactions of contaminants in groundwater systems: documentation and user's guide. DTIC document. Defense Technical Information Center, Fort Belvoir, VA 